\title{
AN APPRAISAL OF THE BARRIERS TO CLIENT INVOLVEMENT IN HEALTH AND SAFETY IN NIGERIA'S CONSTRUCTION INDUSTRY
}

\author{
Nnedinma Umeokafor \\ Department of Built Environment, Faculty of Architecture, Computing \& Humanities, \\ University of Greenwich, London, UK
}

\begin{abstract}
Purpose- The purpose of this paper is to present the findings of a study that identified and assessed the barriers to client involvement in H\&S in the Nigerian construction industry.

Design/methodology/approach- Based on literature review and a pilot study, structured questionnaires were designed and administered to clients and their representatives in ongoing construction projects in Nigeria. Descriptive and inferential statistics were then adopted in analysing the data.
\end{abstract}

Findings- The research reveals that the major barriers to client involvement in H\&S in Nigeria's construction focus on: the gaps created by lack of H\&S legislation in specifying client roles and responsibilities in $\mathrm{H} \& \mathrm{~S}$, trust and confidence in the supply chain, low level of awareness at various levels, procurement issues, the attitudes of various members of project team, and resource-related issues. In total, 20 barriers to client involvement in H\&S were identified and assessed.

Practical implications- Policy makers will find the study beneficial as it provides a good understanding of the issues to address while making policies that seek to involve the client in H\&S in Nigeria.

Originality/value- While the findings offer insight on the barriers to client involvement in H\&S in Nigeria's construction industry, the study also contributes to the discourse in developing countries. The paper recommends transparent steps in procurement, $\mathrm{H} \& \mathrm{~S}$ legislation that factors in economic incentives, and community and financial institutions contributions to involving clients in H\&S. The study is the first attempt to investigate the barriers to client involvement in construction H\&S in Nigeria, contributing to the dearth of H\&S literature in Nigeria.

Keywords: barriers, client, commitment, health and safety (H\&S), Nigeria, owner.

\section{Introduction}

The challenging state of health and safety $(H \& S)$ in the construction industry is well documented in literature (for example, Health and Safety Executive (HSE) 2015a; Kheni et al. 2006; Musonda \& Smallwood 2008a \& b; Umeokafor et al. 2014; Windapo \& Jedege 2013). Indeed, a study of Nigerian construction contractors in 2006 shows that the best accident per worker record among the contractors was 2 accidents per 100 workers, and the best injury per worker record was 5 injuries per 100 workers (Idoro 2011). Similarly, Windapo and Jedege (2013) found that 44\% of 
their respondents (Nigerian contractors) recorded of a low level of compliance with $\mathrm{H} \& \mathrm{~S}$ regulations and witnessed 23 fatalities.

However, antecedent evidence shows that client involvement in H\&S has improved H\&S in the construction industry (Huang \& Hinze 2006; Smallwood 1998; Tuchman 2003). Indeed, Smallwood (1998) found that $76.6 \%$ of his respondents claim that their $\mathrm{H} \& \mathrm{~S}$ performance was improved due to client influence. This is where $72.7 \%$ of his respondents claim that there were fewer accidents due to client influence on H\&S. Huang and Hinze (2006) also report improved H\&S performance in projects where the owners or representatives provided funds above and beyond the contract sum, maintain injury records by contractors, and took part in H\&S programmes and meetings (Huang \& Hinze 2006).

However, in some cases, clients are not committed to H\&S, highly contributing to the poor state of H\&S in developing countries (Musonda \& Smallwood 2008a; Olatunji et al. 2007; Smallwood 1998). Hence, many authors have examine the client as a medium for improving $\mathrm{H} \& \mathrm{~S}$, but the barriers to client involvement in construction $\mathrm{H} \& \mathrm{~S}$ in Nigeria remains under-examined if not unexamined. The extent to which these barriers hinder clients in Nigeria also remains unclear. It also appears that authors have paid little attention to the barriers to client involvement in some developing countries.

In particular, in South Africa, Smallwood (1998) investigates the influence of clients on construction $H \& S$, covering, inter alia, ways that clients can influence contractor $\mathrm{H} \& \mathrm{~S}$ and how frequently clients' decisions influence contractor H\&S. From a private client perspective, Smallwood (2004) goes on to examine the influence of the private client on contractor H\&S. Typically, he focuses on: the level of importance that clients attach to project parameters including project $\mathrm{H} \& \mathrm{~S}$ and public $\mathrm{H} \& \mathrm{~S}$; the implications of negative $\mathrm{H} \& S$ on various project parameters; inter alia, the efforts of various project stakeholders in improving H\&S on construction projects (Smallwood 2004). In the following year, in investigating the role of $H \& S$ in construction marketing, Smallwood (2005) examines the rate 'at which clients require/undertake/request various H\&S related actions/interventions/submissions'. Again in South Africa, Musonda and Smallwood (2008a) appraise the attitude and commitment of client to construction H\&S. From a Hong Kong perspective, the contribution of the client to construction $H \& S$ on public and private projects is examined (Hung 2006). Equally, other studies centre on investigating the relationship between client involvement in H\&S and project performance in terms of H\&S (Huang \& Hinze 2006); how clients influence H\&S standards (Sumner \& Farrell 2003); how clients influence H\&S performance in South Africa and Botswana (Musonda et al. 2012). Furthermore, in Botswana and South Africa, Musonda et al. (2013) focus on the influence of the external client environment on their construction H\&S performance. In the US, Toole et al. (2012) focus on understanding the assumed functions of owners in catalysing the prevention of incidents or ensuring H\&S through design so as to motivate and enable them (Toole et al. 2012). In doing this, they also identified some barriers to client involvement in H\&S in terms of prevention through design. Then the dimension of viewing the role of the client in H\&S from various construction stages is then initiated in Kikwasi (2008). This is where in Tanzania, Kikwasi (2008) accesses the traditional and alternative roles of clients on construction $\mathrm{H} \& \mathrm{~S}$ in the construction process, covering the responsibilities of clients 
at various stages such as tendering, design, award of contract, and construction stages. In terms of Nigeria, no study examining barriers to client involvement was found. Most of the studies centre on H\&S practices through one way or another, for example, Olatunji et al. (2007) and Windapo and Jedege (2013), Umeokafor (2015), Waziri et al (2015), Idoro (2008), Agbede et al. (2016) and others examine construction H\&S regulation in Nigeria, for example, Umeokafor et al. (2014), Umeokafor and Isaac (2015).

Consequently, the main objective of this study is to identify and assess the barriers to client involvement in construction H\&S in Nigeria. The awareness that this study creates is timely, as many countries such as the UK and South Africa continue to hold clients accountable for H\&S through H\&S laws, for example, Construction (Design and Management) Regulations (CDM) of 2015 for the UK (see HSE 2015b), and Construction regulations 2014 for South Africa (see Republic of South Africa 2014). Thus, policymakers, property developers, academics, project managers, H\&S practitioners and even clients with interest in client involvement in Nigeria will find the current study beneficial. In advancing the understanding of client involvement in $H \& S$, the study also contributes to the scarcity of H\&S literature in developing countries such as Nigeria and Ghana (Olatunji et al. 2007; Puplampu \& Quartey 2012). First of all, literature on construction H\&S, covering how clients can improve $\mathrm{H} \& \mathrm{~S}$ is reviewed. Thereafter, the literature review concludes by identifying the barriers to client involvement in construction H\&S. The research methodology is then explained. Subsequently, the quantitative survey results are presented and discussed. Lastly, the conclusions and recommendations are then presented.

\section{Literature survey}

\section{Brief profile of the construction industry}

The construction industry is involved in building and civil engineering activities. The building aspect involves residential and non-residential projects (in both the formal and informal sectors) while the civil engineering aspect involves projects such as bridges, dams, among many, roads (mainly in the formal sector). The life cycle of construction products/projects mainly involves three core stage, preconstruction, construction and post-construction. The person or organisation that pays for the construction product, the owner or the representative of the owner is conceptualised as the client (Alinaitwe 2008). Consequently, the client can be viewed as core and strategic in the construction industry including its supply chain. The industry is a significant contributor to the economies of many countries employing a significant labour force.

\section{Health and safety in the construction industry}

In developed countries such as Britain, there has been an improvement in the H\&S record of the construction industry (HSE 2015a), but based on data from HSE (2015a) there is evidence calling for more actions. Indeed, in 2013/14, the economic cost of workplace injury and new cases of work-related ill health in the British construction industry amounts to $£ 0.9$ billion (Pounds) (HSE 2015a). In 2014/15, the said industry recorded 1.7 million lost working days due to workplace injury and work-related ill health (HSE 2015a). 
Literature also shows that construction $\mathrm{H} \& \mathrm{~S}$ in developing countries is poor (Musonda \& Smallwood 2008a, b; Puplampu \& Quartey 2012; Smallwood 1998; Umeokafor et al. 2014) and the general attitude towards H\&S is not impressive. For instance, in Nigeria, the inadequate governmental attention to $H \& S$ and the inadequate $\mathrm{H} \& \mathrm{~S}$ regulatory system are among the major factors that hinder $\mathrm{H} \& \mathrm{~S}$ practices in the Nigerian construction industry (Umeokafor 2015). In fact, there is no local H\&S legislation that covers construction sites and activities (Diugwu et al 2012; Idoro 2008), but the Labour, Safety, Health and Welfare Bill of 2012 that awaits presidential assent will address that. Nonetheless, the little measures towards improving construction $\mathrm{H} \& \mathrm{~S}$ in Nigeria is largely left to the industry or contractors (Idoro 2008; Umeokafor 2015; Umeokafor \& Isaac 2015) who do so at their discretion, capacity and knowledge. This is where H\&S is not a priority in the industry, as Diugwu et al. (2012) suggest. This is exacerbated by the poor attitudes of clients towards H\&S (Umeokafor et al. 2014). Correspondingly, in Botswana, evidence shows that of the project performance parameters (cost, quality, contract period, avoiding litigation and $H \& S$ ), clients view $H \& S$ as the least important, suggesting their attitude towards it (Musonda \& Smallwood 2008a). The above explains the finding of authors such as Olatunji et al. (2007), Waziri et al (2015), Agbede et al. (2016) and Windapo and Jedege (2013) who statistically evidence the implications of the above. Typically, in a study of construction contractors in South West of Nigeria Agbede et al. (2016) shows that in H\&S practices, (within the elements of planning and implementing, performance measurement, and review/auditing) only $13 \%$ of the contractors surveyed reviewed and updated risk assessments. Further, only $15 \%$ trained site safety supervisors/managers, $17 \%$ claimed to have H\&S departments, and $16 \%$ assessed the competence of workers and subcontractors (Agbede et al. 2016). Although Agbede et al. (2016) report on one out of the six geopolitical zones in Nigeria, the South West includes Lagos state, which is the commercial capital of Nigeria and the "the major hub of construction activities in Nigeria' (Batatunde et al. 2010: 3). If this is the case, then this gives an indication of the magnitude of $H \& S$ problems in Nigeria. Furthermore, earlier, in a study of 30 construction projects in Nigeria, Olatunji et al. (2007) found, among many, no steps to alleviating occupational hazards on construction sites and the low rate of H\&S training. They go on to find a fatality and disability record of 17 persons on average per year due to occupational hazards during construction (Olatunji et al. 2007). The H\&S statistics reported by Idoro (2011) and Windapo and Jegede (2013) in the introductory section also show the poor H\&S record of the Nigeria construction industry.

\section{Client role and practices in improving construction health and safety}

The client is best described as the pivot of the construction supply chain, strategically positioned to stir management commitment to $\mathrm{H} \& \mathrm{~S}$ in the projects and, some times, in organisations. Steps taken by clients can be reactive, proactive or active or even the last two, but proactive and active in some cases are more effective, as they seek to prevent incidents at various phases of the construction. On the risk control hierarchy (NERC 2014), client H\&S activities at the preconstruction stage are emphasised the upper level of the risk control hierarchy (elimination, substitution and engineering control stages) influencing other risk control measures. This hierarchical concept involves taking steps in the hierarchy in order of priority to prevent and/or control risks (NERC 2014). 
As the financer or commissioner of construction projects (Hung 2006), clients have to be satisfied by the contractors and designers, so the clients can insist that contractors adhere to safety standards. Even prior to awarding contracts, clients can vet contractors for those that have good H\&S records (Business Roundtable 1991; Musonda \& Smallwood 2008a), in turn, benefiting from such in various ways. The client can make permit to work mandatory for contractors, provide H\&S guidelines to contractors, conduct H\&S inspections and audits, set H\&S goals, brief design teams to ensure that $\mathrm{H} \& \mathrm{~S}$ is incorporated right from the design stage (Business Roundtable 1991; Huang \& Hinze 2006; Hinze 2005; Musonda \& Smallwood 2008a; Smallwood 1998, 2004). The client can also provide sufficient funds for $H \& S$, ensuring that $\mathrm{H} \& \mathrm{~S}$ is included in the terms of the contract and actively take part in H\&S at the construction stage of the project (Hinze 2005; Huang \& Hinze 2006). Also, the client can invest in H\&S just as consultants do (cf. Musonda \& Smallwood 2008b).

\section{Identifying barriers to client involvement in construction health and safety}

It is noted that the fears of incurring additional liability bars clients from being involved in H\&S practices (Sikes et al. 2000 in Huang \& Hinze 2006; Toole et al. 2012). This makes the client take up more of the active roles (Huang \& Hinze 2006).

Smallwood (1998) notes that lack of resources and expertise can hinder small clients from participating in H\&S (cf. Toole et al. 2012). Furthermore, an inference can be made from Smallwood (1998) in that the points below can bar clients from being involved in H\&S. These include: lack of support from industry association and bodies, inadequate code of conduct that factors in the types and sizes of clients, and lack of legislation that requires a mandatory excess of the budget cost (Smallwood 1998).

The same can be said of the lack of legislation specifying client roles and responsibilities as regulations (such as the CDM regulations of 2015) do (see HSE 2015a). As a result, clients may not know their responsibilities. Even if they know, they may shift the responsibilities to others in the project team (Kikwasi 2008). Worse still, if the client is not legally assigned H\&S roles and responsibilities, they cannot be prosecuted in that regard. Similarly, when additional funds in excess of the contract sum are provided for H\&S, H\&S can be improved (Huang \& Hinze 2006), but when there is no legislative backing for this, clients are not legally obliged to provide funds in excess of the contract sum.

The issue of the structure or category of construction is noted in Umeokafor et al. (2014) where they suggest that the informal construction methods in Nigeria can hinder client involvement in H\&S. They go on to make a case for lack of awareness as a factor for non-compliance with H\&S regulations (Umeokafor et al. 2014). This can be transferable to the current discourse in that when clients do not understand or know their responsibilities in ensuring the safety and health of their indirect employees, they will not take part in H\&S. This can also be in the form of a lack of awareness of the benefits of H\&S in reducing cost, saving time, preventing litigations and protecting the image of clients.

While clients may not want to interfere with the activities of the contractors, when safety concerns arise on construction activities or sites (Emmons 2007), they should understand that it is a moral responsibility (Business Roundtable 1991) and in some 
cases a legal responsibility to ensure H\&S. This can hinder clients from getting involved in $\mathrm{H} \& \mathrm{~S}$ practices. However, when client involvement in $\mathrm{H} \& \mathrm{~S}$ is not carefully and well thought out, it can damage the relationship between the client and contractor and may even affect productivity (Business Roundtable 1991; Hung 2006). This may also hinder the client from getting involved in H\&S. Business Roundtable (1991) and Hung (2006), however, conclude that degree of client involvement in H\&S should involve adequate planning and carefulness. Furthermore, inferring from the works of Business Roundtable (1991) and Toole et al. (2012), it can be seen that an improper communication channel between owner/client and contractors and/or designers can be a barrier to clients.

From a socio-cultural perspective, the works of authors make a case for the discourse. For instance, Umeokafor (2015) covers areas such as religious consciousness, corruption and beliefs as the contextual factors that influence $\mathrm{H} \& \mathrm{~S}$ practices in Nigeria. These can be replicated in the case of the client, as barriers. Typically, if clients have beliefs that there will be no incident during their project, they may view H\&S as unimportant leaving it to fate. Toole et al. (2012) suggest that the lack of accountability can also be a barrier. If the client has concerns about accountability or corruption in the contracting and/or consulting organisations, the client may be sceptical to fund $H \& S$, fearing that $H \& S$ activities will not be carried out as agreed. As economic factors are found to significantly make clients engage in H\&S (Musonda \& Pretorius 2015), lack of funds (which can be an economic factor) can be a barrier to clients (Toole et al. 2012) especially small project clients, but if they can finance projects, they should also finance $H \& S$. However, in practice, many clients who are financially capable in terms of H\&S will use 'lack of funds' as an excuse.

Equally important are the attitudes of contractors and consultants towards H\&S. Kheni at al. (2006) found that consultants have little impact on H\&S because of their attitudes towards it. They also found contractors' attitude towards H\&S in Ghana to be poor in that they prioritise profit-making over $H \& S$, for example, failure to provide PPE, employing incompetent workers (Kheni at al. 2006). The same arguments can be made in terms of Nigeria. Because these contractors and/or consultants want to maximise profit, they may directly or indirectly resist H\&S or even sabotage the efforts of the clients in terms of H\&S. If this is the case, it can be argued that the attitudes of contractors and/or consultants can hinder clients from engaging in H\&S.

\section{Research methodology}

The research approach involved a review of literature and distribution of structured questionnaires to clients and their representatives in Nigeria. The structured questionnaire survey was guided by a positivist method, as it is suitable for addressing the research question because of the ontological position.

\section{Data collection instrument}

The first section of the questionnaire identified the profile of the sample, and the second section assessed twenty barriers to client involvement in construction H\&S (that have been identified through literature review), using Likert-scaled questions from ' 1 ', strongly disagree; to ' 5 ', strongly agree. The twenty barriers assessed cover: economic and financial factors, legislative factors, awareness related factors at various levels, and social issues such as corruption. Other factors are not limited to: industry 
activities-factors such as procurement, relationship among the project stakeholders. A reliability test of the data collection instrument was conducted using Cronbach Alpha test, and it showed a value of .878 . This suggests that the data collection instrument is reliable.

\section{Sampling and data collection}

The questionnaires were piloted to consultants, including academics in Abuja, Anambra, Ebonyi, and Enugu states. Upon receipt of the responses to the questionnaires, it was revised and improved with interviews of three construction professionals. This was aimed at improving the data collection instrument that will, in turn, ensure rigour in the research. The academics were asked to complete it based on a recent project they completed for a client. It is common practice for academics to engage in private practice in addition to their academic activities.

A preliminary survey of on-going construction projects was conducted in 4 states (Ekiti, Kogi, Enugu and Rivers), covering four geopolitical zones (North Central, south South, South East and South West). The preliminary survey showed 249 projects; this was then used as the population. There are six geopolitical zones in Nigeria and a lot of the states in one geopolitical zone, North East, have been destabilised by terrorism and insurgency leaving a lot of the states inhabitable as at the time of collecting the data. Consequently, no data was collected from the North East geopolitical zone. The preliminary survey was conducted because there is no reliable comprehensive data of clients in the study population. This is consistent with studies such as Idoro (2012). The questionnaires were distributed to owners/clients and/or their representatives. These client representatives who must be working with the client in the capacity of project leader included architects, builders, engineers and project managers (Table 1). Many of the sites were visited or contacted more than twice to increase the response rate. Sampling consultants such as architects in studies of this nature where there is the need to appraise client actions or attitudes is consistent with studies such as Alinaitwe (2008). The concept of collected data from consultants who work with clients is underpinned by the fact that they are embedded in the project, overseeing it from the preconstruction to handover stage, thus are even more knowledgeable than the clients in addressing the discourse of the current study (Alinaitwe 2008). Also, these consultants are likely to objectively address the issues, taking into account their expertise and experiences in the assessment. From the population, thirty projects were randomly selected from each state as the sample, $48.2 \%$ of the population. Of the distributed questionnaires, ninety-eight useable questionnaires were returned, a response rate of $81.7 \%$.

\section{Data analysis}

The data were analysed using Statistical Package for Social Science (SPSS) where descriptive (mean) and inferential statistics (Mann-Whitney U test) were adopted. The ground for adopting the nonparametric test is because the study does not meet the requirements of a parametric test. The next section presents and discusses the results of the research, with reference to literature.

\section{Results and discussion}

Description of sample 
Twenty-nine clients and sixty-nine client representatives (consultants) from public and private (building and civil engineering) projects completed the ninety-eight questionnaires. Private clients were corporate organisations, individuals, NGOs, while public clients were parastatals, federal, state and local governments. Twenty-nine clients, (17 from public client organisations and 12 from private clients organisations), participated in the study where all but three of the clients have over five years of experience in the industry. Table 1 shows the description of the consultants and client representatives. It shows that 69 client representatives including consultants participated in the study. It can be argued that although 15 respondents had less than five years of experience, the rest have over five year's experience and the questions were based on an on-going project. As a result, their years of experience may have little or no influence on their responses in the current study.

Table 1: Description of consultants and client representatives

\begin{tabular}{|c|c|c|c|c|c|c|}
\hline \multirow[t]{2}{*}{ Category } & \multirow[t]{2}{*}{ Position } & & \multicolumn{4}{|c|}{ Years of experience } \\
\hline & & $0-5$ & $6-10$ & $11-15$ & $16-20$ & $21-25$ \\
\hline \multirow{6}{*}{$\begin{array}{l}\text { Private client } \\
\text { organisations }\end{array}$} & Architect & 3 & 1 & - & 3 & 2 \\
\hline & Engineer & 2 & 2 & - & 3 & 1 \\
\hline & Builder & 2 & & 1 & 2 & 1 \\
\hline & Project manager & 1 & & & & \\
\hline & Quantity surveyor & & 3 & 1 & 2 & \\
\hline & $\begin{array}{l}\text { Other client } \\
\text { representative }\end{array}$ & 2 & & & & \\
\hline Total & & & & 30 & & \\
\hline \multirow{6}{*}{$\begin{array}{l}\text { Public client } \\
\text { organisations }\end{array}$} & Architect & 4 & 2 & 1 & 2 & 2 \\
\hline & Engineer & 3 & 3 & 3 & 1 & 2 \\
\hline & Builder & 2 & 1 & 2 & & 3 \\
\hline & Project manager & - & & 1 & 1 & \\
\hline & Quantity surveyor & 1 & & 1 & 3 & \\
\hline & $\begin{array}{l}\text { Other client } \\
\text { representative }\end{array}$ & & & & 1 & \\
\hline Total & & & & 39 & & \\
\hline
\end{tabular}

Barriers to client involvement

Remarkably, all but one of the twenty barriers identified and assessed have Mean Scores (MSs) above 2.5 (Table 2), suggesting how seriously the respondents view the factors to hinder clients involvement in H\&S. In particular, from Table 2, it can be seen that the factor with the highest MS of 3.58, is legislation-related and financerelated. The factor ranks $7^{\text {th }}$ for professionals with the MS of 3.62, and for clients, it ranks $2^{\text {nd }}$ with the MS of 3.48. The said factor is where there is no H\&S legislation that requires the client to provide an excess of the budget cost for H\&S. In being remarkable as the major barrier, this factor is also remarkable as a question in that it may be sensitive to clients to answer, but the reverse appears to be the case. However, this suggests that if clients are legally bound to finance H\&S, they may be more committed to it, but this raises concerns as will be seen below.

The aforesaid highest-ranking factor in Table 2 tends to be consistent with the literature (as noted earlier) in that the poor H\&S regulatory environment of Nigeria's construction industry is characterised with inadequate H\&S law (Diugwu et al. 2012; Idoro 2008, Umeokafor 2015), and found to be a major barrier to H\&S (Umeokafor 2015). Granted that there is good evidence that when clients provide funds in excess of the contract sum, there is improved H\&S performance (Huang \& Hinze 2006), it 
should have the legislative backing (cf. Smallwood 1998). Having legislation that requires clients to provide an excess of the budget cost is one thing and compliance (by clients) and enforcement the other. Besides, as earlier stated, there is evidence of poor client commitment to construction H\&S in Nigeria, economically (Olatunji et al. 2007) and clients have been found not to fulfil their financial obligations as required in the conditions of the contracts, for example, bonus payment for prompt completion of works (Alinaitwe 2008). It is also vital to note that Musonda and Pretorius (2015) warn against solely using legislation in enforcing $H \& S$ as it has not yielded the expected results in some countries. The question at this point is 'how will this barrier be addressed in the context of Nigeria, considering compliance issues?

Musonda and Pretorius (2015) found that economic incentives as per H\&S have the same impact as legislation in terms of clients H\&S performance. Therefore, they recommend that economic incentives should be among the factors to be considered in getting the client involved in H\&S or in motivating them (Musonda \& Pretorius 2015). This suggests that in the absence of adequate governmental involvement in $H \& S$, other actors can drive H\&S using economic incentives. It also suggests that $H \& S$ legislation that factors in economic incentives and at the same time requiring an excess of the budget cost for H\&S may not only drive clients but also motivate them and, in turn, contractors. However, this is still subject to governmental involvement in $\mathrm{H} \& \mathrm{~S}$, which is low in Nigeria. Again, this is where other actors such as communities, insurance firms, financial institutions, and pressure groups come in. Although it is outside the scope of this study to develop a roadmap for improving client involvement in $\mathrm{H} \& \mathrm{~S}$, there are some recommendations to this effect in the conclusions and recommendations section.

Table 2: Barriers to client involvement in construction health and safety

\begin{tabular}{|c|c|c|c|c|c|c|}
\hline \multirow[t]{2}{*}{ Barriers to client involvement } & \multicolumn{2}{|c|}{ Consultants } & \multicolumn{2}{|c|}{ Clients } & \multicolumn{2}{|c|}{ Overall } \\
\hline & Mean & Rank & Mean & Rank & Mean & Rank \\
\hline $\begin{array}{l}\text { Lack of legislation that requires mandatory excess of budget } \\
\text { cost for H\&S }\end{array}$ & 3.62 & 7 & 3.48 & 2 & 3.58 & 1 \\
\hline $\begin{array}{l}\text { Corruption - contractor diverts the funds provided by } \\
\text { clients for personal use }\end{array}$ & 3.63 & 6 & 3.34 & 5 & 3.54 & 2 \\
\hline Lack of support from industry association/bodies & 3.57 & 8 & 3.41 & 3 & 3.52 & 3 \\
\hline Construction procurement (including informal) methods & 3.50 & 12 & 3.66 & 1 & 3.51 & 4 \\
\hline Lack of funds & 3.70 & 3 & 3.03 & 9 & 3.50 & 5 \\
\hline Lack of resources and expertise & 3.68 & 4 & 3.00 & 10 & 3.48 & 6 \\
\hline $\begin{array}{l}\text { Inadequate code of conducts that factors in the types and } \\
\text { sizes of clients }\end{array}$ & 3.51 & 11 & 3.38 & 4 & 3.47 & 7 \\
\hline Lack of awareness of the benefits of H\&S in saving time & 3.68 & 4 & 2.97 & 11 & 3.47 & 7 \\
\hline $\begin{array}{l}\text { Lack of legislation specifying responsibilities and roles of } \\
\text { clients in H\&S }\end{array}$ & 3.55 & 10 & 3.24 & 6 & 3.46 & 8 \\
\hline $\begin{array}{l}\text { Lack of awareness of the benefits of } H \& S \text { in protecting the } \\
\text { image of the clients }\end{array}$ & 3.72 & 2 & 2.79 & 13 & 3.45 & 9 \\
\hline Fear of incurring additional liability & 3.48 & 13 & 3.17 & 7 & 3.39 & 10 \\
\hline $\begin{array}{l}\text { Lack of awareness of the benefits of } \mathrm{H} \& \mathrm{~S} \text { in preventing } \\
\text { litigations }\end{array}$ & 3.65 & 5 & 2.69 & 14 & 3.37 & 11 \\
\hline $\begin{array}{l}\text { Attitude of contractors - resisting or sabotaging the efforts } \\
\text { of clients towards H\&S }\end{array}$ & 3.38 & 9 & 3.14 & 8 & 3.31 & 12 \\
\hline $\begin{array}{l}\text { Clients may not want to intervene in the activities of the } \\
\text { contractor }\end{array}$ & 3.45 & 14 & 2.83 & 12 & 3.27 & 13 \\
\hline $\begin{array}{l}\text { Improper communication channel between the owner and } \\
\text { the contractor }\end{array}$ & 3.51 & 11 & 2.69 & 15 & 3.27 & 13 \\
\hline Lack of awareness of the benefits of $H \& S$ in reducing cost & 3.36 & 15 & 3.00 & 10 & 3.26 & 14 \\
\hline
\end{tabular}




\begin{tabular}{|c|c|c|c|c|c|c|}
\hline Damaged relationship between the contractor and the client & 3.33 & 16 & 2.69 & 15 & 3.14 & 15 \\
\hline $\begin{array}{l}\text { Attitude of designers - resistance from designers such as } \\
\text { architects to engage in H\&S }\end{array}$ & 3.16 & 17 & 2.21 & 18 & 2.88 & 16 \\
\hline Religious consciousness/beliefs & 2.71 & 18 & 2.38 & 17 & 2.61 & 17 \\
\hline $\begin{array}{l}\text { Lack of awareness - clients do not understand or know } \\
\text { their responsibilities }\end{array}$ & 3.73 & 1 & 2.51 & 16 & 1.14 & 18 \\
\hline
\end{tabular}

Although 'corruption' where the client provides funds for H\&S and it is diverted for personal use ranks $6^{\text {th }}$ for professionals with the MS of 3.63 and $5^{\text {th }}$ for clients with the MS of 3.34, it ranks second overall with the MS of 3.54 (Table 2). This is consistent with the literature where corruption is reported to hinder H\&S in Nigeria (Omeife \& Windapo 2013; Umeokafor et al. 2014; Umeokafor 2015). Indeed, there is good evidence of corruption hindering H\&S at the industry level, private and public sector levels (Umeokafor 2015). Umeokafor (2015) in trying to explain the extent of corruption in Nigeria opines that corruption has become commonplace in Nigeria in that it has been redefined to terms such as 'appreciation'. Some construction professionals are not left out in corrupt practices (Omeife \& Windapo 2013). This also includes developed countries such as the UK where Teodorescu (2016) reports a Chartered Institute of Building Study in 2013 where $48 \%$ of the respondents view corruption as commonplace in the industry. If this is the case, this means that clients may not have confidence in contractors and/or consultants, and understandably, they will not allocate funds for $H \& S$, especially as it is not a statutory requirement in Nigeria as at the time of writing this paper. However, there are suggested recommendations that address this in the conclusions and recommendations section of this paper.

Furthermore, Table 2 shows that 'lack of support from industry association/bodies' ranks $8^{\text {th }}$ with the MS of 3.57 for professionals and ranks $3^{\text {rd }}$ for clients with the MS of 3.41. It then goes further to rank $3^{\text {rd }}$ overall with the MS of 3.52. The role of the industry in improving $\mathrm{H} \& \mathrm{~S}$ cannot be over-emphasised. Industry or employee associations have been found to contribute to improving H\&S in developing countries through enforcing H\&S laws in workplaces, increasing awareness of H\&S (Kheni et al. 2006). Industry associations can help through education programmes, advising and supporting the client on $\mathrm{H} \& \mathrm{~S}$, and even ensuring that contractors adhere to H\&S terms in the contracts. They have social, and moral responsibilities to H\&S in the industry. Meanwhile, lack of industry support for H\&S also contributes to 'lack of awareness' at various levels as will be seen in Table 2 and as discussed later in this paper.

Construction procurement (including informal) methods in Nigeria ranks $4^{\text {th }}$ fourth with the MS of 3.51; it ranks $\mathrm{I}^{\text {st }}$ for clients with the MS of 3.66 , but ranks $12^{\text {th }}$ for professional with the MS of 3.50 (Table 2). This tends to be consistent with the finding of Umeokafor (2015) that informal procurement routes in the industry influence $H \& S$ practices. Although the current study does not specify the particular procurement route, Babatunde et al. (2010) found that traditional procurement route is dominant in Nigeria, with almost half of all the projects adopting it. Langdon (2011) found that when projects are procured through the traditional route, H\&S is given little consideration as against time, cost and quality, which are given higher attention. The Traditional procurement method means that the design, bid and construction are separate stages in that the client appoints the designer to design the structure and then invites contractors to bid before the qualified contractor is selected to build. 
Equally important are the availability of funds and resources (such as expertise), which ranks $5^{\text {th }}$ (overall) with the MS of 3.50 and $6^{\text {th }}$ (overall) with the MS of 3.48 , respectively (Table 2). Further, lack of funds ranks $3^{\text {rd }}$ for consultants with the MS of 3.70 and ranks $9^{\text {th }}$ for clients with the MS of 3.03. If clients claim to be short of funds for $H \& S$, they will not provide the fund for $H \& S$ thus contractors will lack funds. As a result, for the contractor, H\&S may no longer be a priority, especially among small and medium scale firms who struggle to finance projects (Alinaitwe 2008; cf. Umeokafor 2015). In terms of the availability of resources including expertise, the position of Smallwood (1998) that is noted elsewhere in this paper is adduced in support. He notes that lack of resources and expertise can hinder client involvement in H\&S (Smallwood 1998). When clients lack competent persons to handle H\&S issues such as advising the clients on steps to take, the client awareness level of H\&S is low. This, in turn, significantly hinders H\&S as can be seen in Table 2.

Writing about the lack of awareness at various levels, Table 2 evidences them as significant. Specifically, the respondents emphasise 'clients lack of awareness of the benefits of H\&S in saving construction time' as a barrier, ranking $7^{\text {th }}$ (overall) with the MS of 3.47. Equally, while the lack of awareness of the benefits of H\&S in protecting the image of clients ranks $9^{\text {th }}$ (overall) with the MS of 3.45, lack of awareness of the benefits of H\&S in preventing litigations ranks $11^{\text {th }}$ (overall) with the MS of 3.37. The lowest ranking factor is awareness-related - clients do not understand their responsibilities in terms of H\&S with the MS of 1.14. On face value, Table 2 shows that awareness-related factors rank higher for the professionals in all but one factor 'Lack of awareness of the benefits of H\&S in reducing cost', but the results in Table 3 accept the differences in all five factors, but one, 'Lack of awareness of the benefits of H\&S in saving time'. The implications of this are further discussed later in this paper. Lack of awareness is reported in the literature to impact on H\&S in Nigeria (see Omeife \& Windapo 2013; Umeokafor et al. 2014). In particular, Omeife and Windapo (2013) agree that lack of awareness results in patronising quacks in the construction industry in that some clients are ignorant of the right professionals to consult for building projects or they are ignorant of the correct procedures to take in the building process. As a result, they fall into the hands of the quacks. In affirmation, Umeokafor et al. (2014) demonstrate that lack of awareness hinders compliance with H\&S legislation. Evidence from Diugwu et al. (2012) and Musonda and Smallwood (2008b), also emphasises the lack of awareness in terms H\&S in Nigeria and Botswana, respectively. Based on these findings, it is understandable why clients may not be involved in H\&S, especially if they do not understand the economic benefits (a factor that ranks $14^{\text {th }}$ with the MS of 3.26). If clients understand the benefits of H\&S, it can motivate them to engage in H\&S. Economic motivation for engaging in $H \& S$ is adequately covered in the literature, for example, Musonda and Pretorius (2015), Umeokafor et al. (2014), Umeokafor and Isaac (2015).

Again, another legislation-related factor is also viewed to hinder client involvement in $\mathrm{H} \& \mathrm{~S}$. This is where there is no legislation that specifies the roles and responsibilities of clients in terms of H\&S, ranking $8^{\text {th }}$ (overall) with the MS of 3.46 (Table 2). While on face value, Table 2 shows a difference in the views of the two groups with consultants ranking $10^{\text {th }}$ with the MS of 3.55 and clients $6^{\text {th }}$ with the MS of 3.24 , Table 3 confirms the difference. This implies that although both groups agree that the factor in question is a barrier, the level of impact the consultants ascribe to the factor 
is more than the level of impact the client ascribe to it. This may also explain the awareness factor relating to this responsibility which ranks $18^{\text {th }}$ (Table 2 ). Again, the arguments on the regulatory environment of Nigeria's construction industry can be replicated here. This is where there is no local H\&S legislation covering the industry (Idoro 2008) and some of the adopted ones, which specify the roles and responsibilities of the client, are not enforceable in Nigeria (Umeokafor \& Isaac 2015). As a result, there may be a wrong conceptualisation of responsibilities among the stakeholders (Kikwasi 2008) as will be seen in the next paragraph.

According to Table 2, while the 'attitude of contractors - resisting or sabotaging the efforts of clients towards H\&S' ranks $12^{\text {th }}$ (overall) with the MS of 3.31, the 'attitude of designers- resistance from designers such as architects to engage in H\&S' ranks $16^{\text {th }}$ with the MS of 2.88. In addition to the discussion on the attitudes of contractors and consultants towards H\&S in the literature survey section, this may also occur by clients viewing H\&S as the contractors' responsibility (Kikwasi 2008), thus transferring all the risk to the contractor (Olatunji et al. 2007) and even asking the contractor to engage in some $\mathrm{H} \& \mathrm{~S}$ practices such as the provision of PPE. Conversely, the contractor may view it as the clients' responsibility, resisting adherence to the request of the client because the client may not have provided funds for $H \& S$ in the contract sum. Additionally, it can also occur in various ways as discussed elsewhere in this paper where the contractor diverts funds for H\&S for personal use or as Olatunji et al. (2007) note, the contractor can transfer the risk absorbed from the client to the workers.

\section{Comparison of the responses of consultants and clients on the barriers to client involvement in health and safety in the construction industry.}

A Mann-Whitney test was conducted to see if there is a significant difference or not between the responses of consultants and clients on the barriers to client involvement in construction H\&S. A significance level of equal to .05 or $<.05$ was used for the analysis. This means that for the null hypothesis - there is no difference in the responses of consultants and clients on the barriers to client involvement in construction H\&S in Table 2 - to be accepted, the $p$-value will be greater than .05 or equal to .05 , else, it will be rejected.

The result of the analysis as can be seen in Table 2 shows that there are significant differences in the responses of consultants and clients on nine barriers to client involvement in construction H\&S. The effect size ' $r$ ' was the calculated using $r=$ $\mathrm{z}$ /square of $\mathrm{N}$, where $\mathrm{r}$ is the effect size, $\mathrm{Z}$ is the $\mathrm{S}$ score, and $\mathrm{N}$ is the number of cases - 98. According to Cohen (1988), the effect size can be considered as small if = 0.20 , medium if $=0.50$, then large if $=0.80$. Sullivan and Feinn (2012) notes that effect size is the main finding in quantitative studies in that while the $p$-value shows that there is a difference, effect size shows the extent of the difference between the groups, thus reporting it is vital.

Table 3: Result of Mann-Whitney Test

\begin{tabular}{llccc}
\hline Barriers to client involvement & $\begin{array}{l}\text { Mann- } \\
\text { Whitney } \\
(\mathrm{U})\end{array}$ & $\begin{array}{l}\text { Asymp. } \\
\text { Sig (2- } \\
\text { tailed) }\end{array}$ & $\begin{array}{l}\mathrm{Z} \text { score } \\
\mathrm{r}=\text { zquare } \\
\text { of N }\end{array}$ & Decision \\
\hline $\begin{array}{l}\text { Lack of legislation that requires mandatory excess of } \\
\text { budget cost for H\&S }\end{array}$ & 986.0 & .904 & -1.244 & Accept \\
\hline
\end{tabular}




\begin{tabular}{|c|c|c|c|c|c|}
\hline $\begin{array}{l}\text { Corruption - contractor diverts the funds provided by } \\
\text { clients for personal use }\end{array}$ & 846.5 & .216 & -1.235 & & Accept \\
\hline Lack of support from industry association/bodies & 954.0 & .692 & -.397 & & Accept \\
\hline Construction procurement (including informal) methods & 888.0 & .352 & -.932 & & Accept \\
\hline Lack of funds & 671.5 & .006 & -2.737 & -0.276 & Reject \\
\hline Lack of resources and expertise & 701.0 & .012 & -2.506 & -0.253 & Reject \\
\hline $\begin{array}{l}\text { Inadequate code of conducts that factors in the types and } \\
\text { sizes of clients }\end{array}$ & 976.0 & .841 & -.200 & & Accept \\
\hline Lack of awareness of the benefits of $H \& S$ in saving time & 747.5 & 0.41 & -.2 .042 & & Accept \\
\hline $\begin{array}{l}\text { Lack of legislation specifying responsibilities and roles of } \\
\text { clients in H\&S }\end{array}$ & 846.5 & .213 & -.121 & & Accept \\
\hline $\begin{array}{l}\text { Lack of awareness of the benefits of H\&S in protecting the } \\
\text { image of the clients }\end{array}$ & 548.5 & .001 & -3.365 & -0.339 & Reject \\
\hline Fear of incurring additional liability & 907.5 & .449 & -.758 & & Accept \\
\hline $\begin{array}{l}\text { Lack of awareness of the benefits of H\&S in preventing } \\
\text { litigations }\end{array}$ & 592.5 & .001 & -3.286 & -0.331 & Reject \\
\hline $\begin{array}{l}\text { Attitude of contractors - resisting or sabotaging the } \\
\text { efforts of clients towards H\&S }\end{array}$ & 849.5 & .206 & -1.265 & & Accept \\
\hline $\begin{array}{l}\text { Clients may not want to intervene in the activities of the } \\
\text { contractor }\end{array}$ & 723.5 & .022 & -2.287 & -0.231 & Reject \\
\hline $\begin{array}{l}\text { Improper communication channel between the owner and } \\
\text { the contractor }\end{array}$ & 513.5 & .000 & -4.119 & -0.416 & Reject \\
\hline Lack of awareness of the benefits of $\mathrm{H} \& \mathrm{~S}$ in reducing cost & 853.5 & .241 & -1.172 & & Accept \\
\hline Damaged relationship between the contractor and the client & 659.0 & .004 & -2.841 & -0.286 & Reject \\
\hline $\begin{array}{l}\text { Attitude of designers - resistance from designers such as } \\
\text { architects to engage in H\&S }\end{array}$ & 506.5 & .000 & -4.096 & -0.413 & Reject \\
\hline Religious consciousness/beliefs & 826.5 & .216 & -1.380 & & Accept \\
\hline $\begin{array}{l}\text { Lack of awareness - clients do not understand or know } \\
\text { their responsibilities }\end{array}$ & 433.5 & .000 & -4.578 & -0.462 & Reject \\
\hline
\end{tabular}

If that is the case, then according to Table 3 , the factors with significantly different responses which effect size as medium are 'lack of funds', 'lack of resources and expertise', 'clients may not want to intervene in the activities of the contractor', 'damaged relationship between the contractor and the client'. The analysis further shows that the following responses of the two groups, consultants and clients are also significant on the factors with a medium effect thus: 'lack of awareness of the benefits of H\&S in protecting the image of the clients', 'lack of awareness of the benefits of $\mathrm{H} \& \mathrm{~S}$ in preventing litigations', 'improper communication channel between the owner and the contractor', 'attitude of designers- resistance from designers such as architects to engage in H\&S', 'Lack of awareness - clients do not understand or know their responsibilities'.

The implication of the analysis in Table 3 are that the factors with no significant difference in the responses of consultants and clients (that is those with accept decisions in Table 3 ) is that there is consensus on the barriers hindering the clients, and this can be by chance, thus not reliable. However, those with significant differences imply that it is unlikely that there is no agreement on barriers hindering the clients; it is unlikely to be due to chance. This emphasises that the results are not by chance $(5 \%-p$-value $)$, confirming that they are reliable.

\section{PRACTICAL IMPLICATIONS}

The practical implications of the research include the imperativeness of enforced client responsibilities in terms of $\mathrm{H} \& \mathrm{~S}$, a point for policymakers, pressure groups and industry associations. Typically, the research implies that legislative backing for the 
mandatory excess of the budget cost for $H \& S$ will contribute to improving $H \& S$, especially for SMEs who are the majority of the contractors. Also, the impact of corruption in the construction industry remains emphasised in the current research hence measure as seen in the next section is needed so as to encourage and ensure client involvement in H\&S. Contractors, policymakers, academics, and industry associations are now aware that with improved client awareness on H\&S, the level of client involvement in H\&S is likely to improve. Based on the evidence in the study on the awareness-related barriers, it may be logical to conclude that if clients understand their responsibilities and the benefits of H\&S to them, they may be more involved in $\mathrm{H} \& \mathrm{~S}$. Furthermore, as the client is strategic in the construction supply chain and there is evidence in the literature that economic incentives would improve client involvement even at the self-compliance level, it is logical that policymakers consider the aforesaid in policymaking. Borrowing from the comments of one of the reviewers to scope the research to the international community or readers, the current study can encourage and reinforce the imperativeness of existing effective H\&S systems with higher level of client involvement. This is because the current study can serve a good contrasting standard.

Drawing on the literature survey and results, discussion, and practical implications sections, the next section concludes the paper and attempts to make practical recommendations. The limitations of the study and suggested areas of further research are also noted.

\section{CONCLUSIONS AND RECOMMENDATIONS}

This study identifies and assesses the barriers to client involvement in construction $H \& S$ in Nigeria. This was inspired by the poor state of H\&S in developing countries such as Nigeria and the gap in knowledge of the barriers to client involvement in H\&S. All but one of the twenty identified and assessed factors were established to be above the midpoint of 2.5 , suggesting how seriously these factors hinder client involvement. There are differences in the views if the clients and consultants in all the 20 barriers, but the inferential statistics show the significant differences in the responses of the clients and consultants in all but nine barriers as likely due to chance. However, the 'effect sizes' of the differences are all at a medium level. These nine factors are not limited to: 'attitude of designers - resistance from designers such as architects to engage in H\&S', 'lack of awareness - clients do not understand or know their responsibilities', lack of awareness of the benefits of H\&S in protecting the image of the clients' and 'improper communication channel between the owner and the contractor'.

Nonetheless, there is good evidence in the study that the major reason for client noninvolvement in $H \& S$ is because it is not a legal requirement to provide funds for $H \& S$ in excess of the contract sum. The study goes further to establish that client lack of trust and confidence in the contractor due to their unethical practices result in clients not committing or taking part in H\&S. This is where contractors divert funds meant for $H \& S$ for personal use. Furthermore, it is evident in the study that with adequate support from industry associations for the clients in terms of H\&S, clients' contribution or involvement in H\&S will be improved. However, it is possible that the problem of client involvement starts during the preconstruction stage. Indeed, the procurement methods, (perhaps the traditional procurement route which is dominant 
in the industry) do not support the client in terms of H\&S. All above, this calls for a more transparent procurement approach and more enforced H\&S responsibility on the client requiring the provision of the excess of the budget cost. Furthermore, all these factors tend to be fueled by lack of awareness at various levels, including lack of awareness of the economic benefits and social legitimacy benefits of H\&S.

Based on the findings and drawing on literature discussion, the following are recommended. First, efforts towards getting clients involved in H\&S should concentrate on bestowing more responsibility on them. Admitted that as at the time of writing this paper, the Nigerian construction industry is yet to have a local H\&S law that holds the client more responsible for $H \& S$, communities, financial institutions, insurance firms, industry associations, professional bodies and pressure groups can take up this responsibility. While financial institutions that finance construction projects have financial responsibilities to ensure that clients drive H\&S, all the parties above also have moral and social responsibilities. In terms of clients, financial institutions should drive $H \& S$, otherwise, they can act as regulators of H\&S in any capacity. For instance, financial and insurance firms can have economic incentives for their clients to engage in H\&S. Second, however, it is pertinent that the Labour, Safety, Health and Welfare Bill of 2012 (updated in 2016) in Nigeria that is yet to receive presidential ascent should significantly factor in economic incentive measures, motivating the client and ensuring self-compliance. Third, a more transparent procurement method, which takes accountability more seriously, should be encouraged. On completion of projects and even at various stages of the project, there should be an audit of finances relating to $H \& S$ in the project. This is in addition to the client or representatives taking part in the $H \& S$ of the project, including its financial management. Lastly, policymakers, pressure groups, financial and insurance institutions and industry associations should channel more resources on creating awareness on H\&S. For example, industry association should provide H\&S information for their members and even the public while policymakers should prioritise $H \& S$ awareness in policies with emphasis on clients. Financial and insurance firms can provide $H \& S$ information to clients who the finance or insure their projects, demonstrating the benefits including the financial benefits of H\&S. While the study is of Nigeria perspective, authors in other developing countries can use the study as a framework to examine the discourse in the contexts of their countries.

To conclude, it is vital to note some limitations of the study and suggest areas of further research. First, it is recognised that examining clients holistically may mean that the experiences and the views of clients in terms of types of clients (public and private) may be left out. This is because public and private clients have different characteristics, and experience different degrees and types of challenges. Thus, as this study does not address clients based on categories, further investigation is required in this area. Second, the understanding of these barriers will be deeper if there was a qualitative 'touch' on the discourse; thus, further studies of the qualitative paradigm are recommended. For instance, how procurement methods hinder client from engaging in H\&S will offer a deeper understanding of the discourse. Third, further studies can also seek to develop a roadmap or framework for client involvement in construction H\&S in Nigeria, an area outside the scope of this study.

\section{REFERENCES}


- Agbede, J. O., Manu, P., Agbede, O. A. and Mahamadu, A.-M. (2016) 'Health and safety management practices in the Nigerian construction industry: A survey of construction firms in South Western Nigeria'. In: Matthijs, P., Wamelink, H., Giddings, B. and Ku, K., eds. (2016) Proceedings of the CIB World Building Congress 2016: Volume II - Environmental Opportunies and Challenges. Constructing Commitment and Acknowledging Human Experiences.

- Alinaitwe, H. M. (2008). 'An assessment of clients' performance in having an efficient building process in Uganda', Journal of Civil Engineering and Management, Vol. 14 No 2,pp. 73 - 78.

- Babatunde, S.O., Opawole, A. and Ujaddughe, I. C. (2010) 'An Appraisal of Project Procurement Methods in Nigerian Construction Industry', Civil Engineering Dimension, Vol. 2 No 1,pp. 1-7.

- Business Roundtable (1991). 'Improving construction safety performance'. Report A-3. The Business Roundtable, Washington.

- Cohen, J. (1988). 'Statistical power analysis for the behavioral sciences' (2nd ed.). Hillsdale, NJ: Lawrence Earlbaum Associates.

- Diugwu I.A., Baba D. L., and Egila A. E. (2012). 'Effective regulation and level of awareness: An expose of the Nigeria's construction industry', Open Journal of Safety Science and Technology, 2012, Vol. 2, pp.140-146.

- Emmons, J. (2007) Why contractor safety is important for owner: today's owners face a variety of risks when they undertake a construction project. Buildings, Vol. 101 No. 4, p.42(5).

- Federal Republic of Nigeria. Labour, Safety Health and Welfare Bill. 2012.

- Health and Safety Executive (HSE) (2015a) 'Health and safety in construction sector in Great Britain, 2014/15', available at http://www.hse.gov.uk/statistics/industry/construction/construction.pdf (accessed on 28-10-15).

- Health and Safety Executive (HSE) (2015b), 'Managing health and safety in construction: Construction Design and Management', available at http://www.hse.gov.uk/pubns/priced/1153.pdf (accessed on 06-10-15).

- Huang, X. and Hinze, J. (2006), 'Owner's role in construction safety', Journal of Construction Engineering and Management, Vol. 132 No. 2, pp.164 - 173.

- Hung, M. Y. (2006), 'Client's contributions to project safety performance: A comparison between public and private construction projects', unpublished BSc dissertation, University of Hong Kong, Hong Kong, available at http://hub.hku.hk/bitstream/10722/48905/1/b37943145.pdf (accessed on 18 $10-15)$

- Idoro, G. I. (2008), 'Health and safety management efforts as correlates of performance in the Nigerian construction industry', Journal of Civil Engineering and Management. Vol. 14 No4, pp. 277-285.

- Idoro, G. I. (2012), 'Evaluating Levels of Project Planning and their Effects on Performance in the Nigerian Construction Industry', Construction Economics and Building, Vol. 9 No. 2, pp. 39- 50.

- Idoro, G.I. (2011). Comparing Occupational Health and Safety (OHS) Management efforts and Performance of Nigerian Construction Contractors. Journal of Construction in Developing Countries, 16 (2), 151-173. 
- Kheni, N. A., Gibb, A. G. F. and Dainty, A. R. J. (2006), 'The management practices of construction site health and safety by small and medium-sized construction business in developing countries: A case of Ghana'. In: Boyd, D (Ed.), $22^{\text {nd }}$ ARCOM Conference, 4-6 September 2006, Birmingham, pp. 273282.

- Kikwasi, G. J. (2008), 'Client involvement in construction safety and health', in Hinze, J., Bohner, S., and Lew, J. (Ed.), Proc.: CIB W099 International Health and safety Conference: $14^{\text {th }}$ Rinker International Conference, 9- 22 March. Gainesville, Florida, USA, 55 - 67.

- Langdon, D. (2011) 'Health and safety in public sector construction procurement: A follow-up study', HSE books, available on http://www.hse.gov.uk/research/rrpdf/rr848.pdf (accessed 27-05-16)

- Musonda, I. and Pretorius, J. H. C., (2015), 'Effectiveness of economic incentives on cleints' participation in health and safety programmes'. Journal of South African Institution of Civil Engineering, Vol. 57No. 2,pp 2 - 7.

- Musonda, I., Pretorius, J., and Haupt, T. (2013), 'Investigating the role of the external environment to influence clients' health and safety (H\&S) performance in the construction industry', In Kajewski, S., Manley, K. and Hampson, K. Proc. of the 19th CIB World Building Congress, Construction and Society, Brisbane 5-9 May, 2013: pp 122 - 134

- Musonda, I., Pretorius, J. H. C., and Haupt, T. H. (2012), 'Assuring health and safety performance on construction projects: Clients' role and influence', Acta Structilia, Vol. 19 No 1,pp. $71-105$.

- Musonda I. and Smallwood J. (2008a), 'Client commitment and attitude to construction health and safety in Botswana', in Verster J. J. P. and Marx H.J (Eds): Proc.: $5^{\text {th }}$ Postgraduate Construction Industry Development board (cidb) conference, March 16 - 18, Bloemfontein, pg.11-21.

- Musonda, I. and Smallwood, J. (2008b), 'Health and safety (H\&S) awareness and implementation in Botswana's construction industry', Journal of Engineering, Design and Technology, Vol. 6 No 1,pp. 81-90.

- NERC (2014) 'Health and safety procedure No: 12: Risk assessment and Risk management', Vers. 2.1, available at http://www.nerc.ac.uk/about/policy/safety/procedures/procedureriskassessment/ (accessed on 02-02-16)

- Olatunji, O. A., Aje, O. I., Odugboye, 'F. (2007), 'Evaluating Health And Safety Performance of Nigerian Construction Site', CIB World Congress Cape Town, 14-18 May, pp. 1176-1190

- Omeife, C. A. and Windapo, O. A. (2013), 'The impact of national building code on professionalism', Proc.: $43^{\text {rd }}$ Builders Conference/AGM, Abuja, Nigeria, pp 1-12.

- Puplampu, B. B., and Quartey, S. H. (2012), 'Key Issues on occupational health and safety practices in Ghana: A Review. International Journal of Business and Social Science. Vol. 3(19), 151 - 156.

- Republic of South Africa (2014) Government Gazette No 37305 Construction regulations 2014. Pretoria.

- Smallwood, J. (1998), 'Client influence on contractor health and safety in South Africa', Building Research and information, Vol. 26 No 3,pp. 181 - 189

- Smallwood, J. J. (2004), 'The influence of clients on contractors health and safety (H\&S)', In Khosrowshahi, F (Ed), $20^{\text {th }}$ Annual Association of 
Researchers in Construction Management (ARCOM) conference, 1-3 September 2004, Heriot Watt University, Vol. 2, pp.1095 - 105.

- Smallwood, J. (2005), 'The role of optimum health and safety (H\&S) in construction marketing', In: Khosrowshahi, F (Ed.), 21st Annual Association of Researchers in Construction Management (ARCOM) Conference, 7-9 September 2005, SOAS, University of London. Vol. 2,pp. 1097-106.

- Sumner, S. and Farrell, P. (2003), 'The influence of clients on health and safety standards in construction', in Greenwood, D. J. (Ed), $19^{\text {th }}$ Annual Association of Researchers in Construction Management (ARCOM) conference, 3-5 September 2003, University of Brighton, Vol.1, 193 -202.

- Teodorescu, L. (2016). 'Five years on: What impact has the Bribery Act had on construction?' Construction Manager, June 2016, pp 38-39.

- Toole, T. M., Gambatese, J. A., and Abowitz D. A. (2012) 'Final research report: Owners' Role in Facilitating Designing for Construction Safety’, Bucknell University, Lewisburg, available at http://www.facstaff.bucknell.edu/ttoole/Owners'\%20Role $\% 20 \mathrm{in} \% 20$ Facilitatin g\%20DfCS\%20Report.pdf (accessed on 20-04-16)

- Tuchman, J. L. (2003), 'Owners play a major role in site safety' ENR: Engineering News-Record, Vol. 251 No 6,pp. 14.

- Umeokafor, N. I., Umeadi, B. and Jones, K.G. (2014), 'Compliance with Occupational Health and Safety Regulations: A Review of Nigeria's Construction Industry', In Ejohwomu, O. and Oshodi, O. (Eds), $3 r d$ International Conference on Infrastructure Development in Africa, ICIDA 2014, 70 - 81 .

- Umeokafor, N. I (2015), 'An assessment of the influence of contextual environment on health and safety practices in the Nigerian construction industry', In Behm, M and McAleenan (Ed.), Proc.: CIB W099 International Health and safety Conference: Benefitting Workers and Society through inherently safe construction, 10- 11 Sept. Northern Ireland, UK, 397 - 406

- Umeokafor, N. I., and Isaac, D. (2015), 'A framework for analysing the determinants of health and safety self-regulation in the construction industry', in Behm, M and McAleenan (Ed.), Proc.: CIB W099 International Health and safety Conference, 10- 11 Sept. 2015, Northern Ireland, UK, 478 - 487

- Waziri, B. S., Hamma-adama, M., and Kadai (2015), 'Exploring health and safety practices on some Nigeria construction site'. In: Laryea, S. Leiringer, R. (Eds) Procs $6^{\text {th }}$ West Africa Built Environment Research (WABER) Conference, 10 - 12 August, Accra, Ghana, pp. 491-502.

- Windapo, A. O. and Jegede, O. P. (2013), 'A study of heath, safety and environment (HSE) practices of Nigerian construction companies', The professional Builder, Vol. 4 No 1,pp. 92-103. 